\title{
Refleksi Pola Pikir dan Kearifan Lokal Masyarakat Sasak dalam Ranah Pertanian: Sebuah Investigasi atas Fakta Linguistik
}

\author{
Saharudin*) \\ Pos-el: Sahrul_saharuddin@yahoo.com
}

\begin{abstract}
Abstrak
Adanya gempuran dahsyat dan pengaruh-baik disadari ataupun tidakdari proses westernisasi dan globalisasi terutama terhadap pandangan hidup masyarakat kita telah menumbuhkan kekhawatiran. Yakni munculnya rasa khawatir akan lenyapnya jati diri bangsa Indonesia dalam arus westernisasi dan globalisasi. Arus tersebut kini telah membawa kesadaran sebagian dari kita untuk melihat kembali dan menggali dasar-dasar pandangan hidup (kepercayaan, perasaan, dan segala hal terdapat dalam pikiran orang/masyarakat yang berfungsi sebagai motor atau stimulan bagi keberlangsungan dan perubahan moral maupun sosial) yang terpendam dalam berbagai bentuk budaya lokal leluhur kita. Memang tidak bisa disangkal lagi bahwa dalam dasawarsa terakhir ini kesadaran orang untuk menggali kembali kearifan lokal (local wisdom) yang ada pada kelompok masyarakat atau suku tertentu lebih intens. Hal ini terjadi karena ilmu pengetahuan modern ternyata tidak selalu membawa hal yang positif dalam kehidupan. Ilmu pengetahuan pertanian modern yang menghasilkan revolusi hijau, misalnya, menimbulkan sejumlah dampak negatif seperti pemakaian pupuk kimia yang dapat merusak kesuburan tanah dan pemakaian insektisida dan pestisida yang dapat mengganggu keseimbangan alam. Oleh karena itu, orang pun mulai menoleh kembali ke pengetahuan lokal (etnosains) untuk mengetahui bagaimana masyarakat dahulu bertani. Informasi mengenai pengetahuan lokal itu dapat diperoleh dengan berbagai cara, salah satunya ialah dengan meneliti bahasa yang mereka pakai dalam ranah itu. Dalam bahasa terdapat sejumlah leksikon dan bentuk ekpresi lainnya yang dapat memberi petunjuk berharga mengenai bagaimana masyarakat penuturnya memikirkan dunia ini (pola pikir).
\end{abstract}

Kata kunci: budaya lokal, kearifan lokal, pengetahuan lokal

\section{Pendahuluan}

Adanya gempuran dahsyat dan pengaruh -baik disadari ataupun tidak- dari proses westernisasi dan globalisasi terutama

*) Staf Pengajar pada IAI Qamarul Huda dan STKIP Qamarul Huda Bagu, Lombok Tengah, NTB 
terhadap pandangan hidup masyarakat kita telah menumbuhkan kekhawatiran. Yakni munculnya rasa khawatir akan lenyapnya jati diri bangsa Indonesia dalam arus westernisasi dan globalisasi. Arus tersebut kini telah membawa kesadaran sebagian dari kita untuk melihat kembali dan menggali dasar-dasar pandangan hidup (kepercayaan, perasaan dan apa-apa yang terdapat dalam pikiran orang/masyarakat yang berfungsi sebagai motor atau stimulan bagi keberlangsungan dan perubahan moral maupun sosial) yang terpendam dalam berbagai bentuk budaya lokal leluhur kita.

Oleh karena itu, tidak heran jika akhir-akhir ini dalam acara diskusi maupun seminar sangat sering kita mendengar istilah-istilah yang berkaitan dengan keinginan untuk mengangkat kembali nilainilai positif budaya lokal dan warisan intelektual leluhur. Berbagai istilah yang sering terdengar itu seperti: reinterpretasi, revitalisasi, kontekstualisasi, reaktualisasi, dan semisalnya. Pertanyaan yang kemudian muncul dalam manah kita adalah: apakah masyarakat kita sudah begitu jauh meninggalkan nilai-nilai budaya dalam kebudayaannya, sehingga nilai-nilai budaya tersebut perlu diangkat kembali sebagai awig-awig hidup? Ataukah masyarakat kita sudah mulai merasakan kegersangan dan kehampaan hidup ketika budaya global sudah mulai mencabik-cabik budaya mereka, sebagaimana orang Barat sekarang sudah mulai frustasi karena sekuler dan kembali pada postmodern?

Memang tidak bisa disangkal lagi, bahwa dalam dasawarsa terakhir ini kesadaran orang untuk menggali kembali kearifan lokal (local wisdom) yang ada pada kelompok masyarakat atau suku tertentu lebih intens. Hal ini terjadi karena ilmu pengetahuan modern ternyata tidak selalu membawa hal yang positif dalam kehidupan. 
Ilmu pengetahuan pertanian modern yang menghasilkan revolusi hijau, misalnya, menimbulkan sejumlah dampak negatif seperti pemakaian pupuk kimia yang dapat merusak kesuburan tanah dan pemakaian insektisida dan pestisida yang dapat mengganggu keseimbangan alam. Oleh karena itu, orang pun mulai menoleh kembali ke pengetahuan lokal (etnosains) untuk mengetahui bagaimana masyarakat dahulu bertani. Informasi mengenai pengetahuan lokal itu dapat diperoleh dengan berbagai cara, salah satunya ialah dengan meneliti bahasa yang mereka pakai dalam ranah itu. Dalam bahasa terdapat sejumlah leksikon dan bentuk ekspresi lainnya yang dapat memberi petunjuk berharga mengenai bagaimana masyarakat penuturnya memikirkan dunia ini (pola pikir).

Tulisan ini mencoba untuk mengungkap sebagian dari etnosains dalam masyarakat Sasak, yakni pengetahuan mereka dalam dunia pertanian yang terefleksikan melalui data/fakta linguistik berupa mantra seputar dunia pertanian (padi). Ranah pertanian dipilih sebagai objek garapan tulisan ini sangat dekat dengan lingkungan alam dan hemat penulis- termasuk culture complex dalam konteks budaya masyarakat Sasak (komunitas adat dan pedesaan). Dengan demikian, tulisan/makalah ini diharapkan bisa memberikan sumbangsih pengetahuan tentang bagaimana pola pikir masyarakat Sasak (komunitas adat dan pedesaan) dan local wisdomnya terkait dengan pertanian dan lingkungannya; prinsip-prinsip apa yang mereka pegang sehingga keserasian dengan alam dapat tercapai atau tidak menimbulkan kerusakan alam. Dengan kata lain, dari bahasa (alat mencatat dan mentransformasi data pengalaman) dikaji untuk memperoleh informasi $\rightarrow$ pengetahuan $\rightarrow$ kearifan demi survival. 


\section{Pembahasan}

\subsection{Sistem Pertanian Padi Masyarakat Sasak (Tradisional) 2.1.1 Prosesi Pembenihan hingga Penanaman}

Para petani padi di kampung (baca: komunitas adat dan pedesaan) setelah turun hujan akan melakukan berbagai prosesi terkait dengan kegiatan ngaro-ngaréng (bercocok-tanam) di sawah. Mereka mulai dari pemilihan bibit padi yang telah disiapkan setahun yang lalu. Prosesi selanjutnya adalah nêlêp, yakni merendam bibit padi ke telaga atau sungai selama kurang lebih tiga hari tiga malam atau sampai terlihat pembelahan pada kulit benih padi. Sebelum bibit padi ditêlêp, terlebih dahulu dibacakan mantra yang disebut mêntêrên buk.

\section{Bismillahirrahmanirrahim}

(1) Anaq kumulit-mulit, inaq ku ketoq-ketoq, amaq ku kuaqkuaq, side mandi menteren buk tembuak.

Pembacaan mantra di atas dibarengi dengan penaruhan air mên-mên (air penyejuk) yang sudah dicampur atau diramu dalam bejana yang disebut bun (bejana berbentuk bundar, terbuat dari besi, perak, atau tembaga dicampur dengan emas). Isi ramuan dalam bun ini berupa irisan kunyit, berambang putih, daun jonjoq mari (mirip dengan daun pare-pare, tapi lebih pipih dan kecil), kepeng têpong atau uang logam, dan tengkulak (terbuat dari batok kelapa). Air mên-mên tadi kemudian disiramkan ke seluruh bibit padi yang mau direndam dengan menggunakan cebokan berupa tengkulak. Irisan kunyit, berambang putih, dan daun jonjoq mari tadi diselipkan pada semua otak benih padi tersebut. ${ }^{1}$

\footnotetext{
1 Jenis benih padi yang dimaksudkan di sini adalah jenis padi besar, yang dalam konteks petani Sasak (tradisional) disebut paré jamaq, paré bulu, pare lobaq, paré benai, atau jika sudah diikat disebut paré amêt dan sebagainya. Padi semacam
} 
Menurut Amaq Suhar (wawancara 15 Januari 2008), semua jenis bahan atau alat yang dipakai dalam membuat air mên-mên di atas memiliki makna simbolik atau semiotik. 1) Kunyit, bermakna agar buah padi tersebut nantinya kuning-gading seperti warna kunyit itu. 2) Lensune (berambang putih), supaya isi/berasnya putih laksana isi berambang putih. 3) Daun jonjoq mari, agar padi tersebut selalu êmên-bao (sejuk-menyegarkan). Artinya, tidak mengalami gangguan penyakit/hama selama di sawah hingga dimasukkan ke dalam lumbung. 4) Kepeng têpong (uang logam yang berlubang), supaya isi padi berat bagaikan logam. 5) Tengkulak, merupakan simbol tentang alat yang dipakai untuk memandikan benih padi dan (nanti setelah menjadi beras) merupakan alat untuk menceboknya di dalam sêndor (gentong tempat beras, terbuat dari tanah). Dalam ungkapan Sasaknya: iê isiq têpandiq, iê isiq têsédok. 6) Bun, merupakan simbol terhadap lumbung/alang tempat penyimpanan padi.

Setelah prosesi di atas, lalu benih padi direndam. Pada saat direndam (têtêlêp) benih padi tadi dipesan dengan dibacakan mantra berikut.

(2) Ane nani yaq lampak lalo bêlayar tunggang perahu bungkêm empat bulan limen yaq uleq.

'Ayo sekarang [engkau] akan berjalan pergi berlayar dengan menunggangi "perahu bungkêm" selama empat bulan dan tepat lima bulannya pulang.'

Ketika prosesi nêlêp sudah selesai, benih padi tadi berarti telah siap diampar (ditebar) di tempat penyiapan bibit yang disebut dengan pengamparan. Proses ini terjadi selama kurang lebih dua banyak ditanam petani sekarang ini. 
puluh hingga tiga puluh hari. Setelah bibit padi siap ditanam di sawah, para petani Sasak (tradisional) terlebih dahulu melakukan prosesi penanaman padi yang disebut bait mansê (pengambilan/penentuan awal masa tanam). Dalam melakukan bait mansê, terlebih dahulu digunakan jenis tumbuh-tumbuhan seperti daun pandan atau daun pohon bambang baru kemudian ditanami bibit padi pembait mansê (Wawancara dengan Bapak Salmun, 6 Oktober 2007).

Menurut Bapak Salmun (2007), cara pembaitan mansê ialah dengan cara berdiri di tengah-tengah sawah yang hendak ditanami benih padi, lalu melangkah mundur ke belakang tanpa menoleh ke belakang (tidak boleh menoleh ke belakang) setelah menancapkan benih pembait mansê. Ada pula pendapat yang lain, yakni cukup dengan cara menanamkan bibit pembait mansê di dekat jalan masuknya air ke sawah (êmbang-êmbang, bêlong bangkêt). Visualisasinya seperti pada gambar di bawah ini.

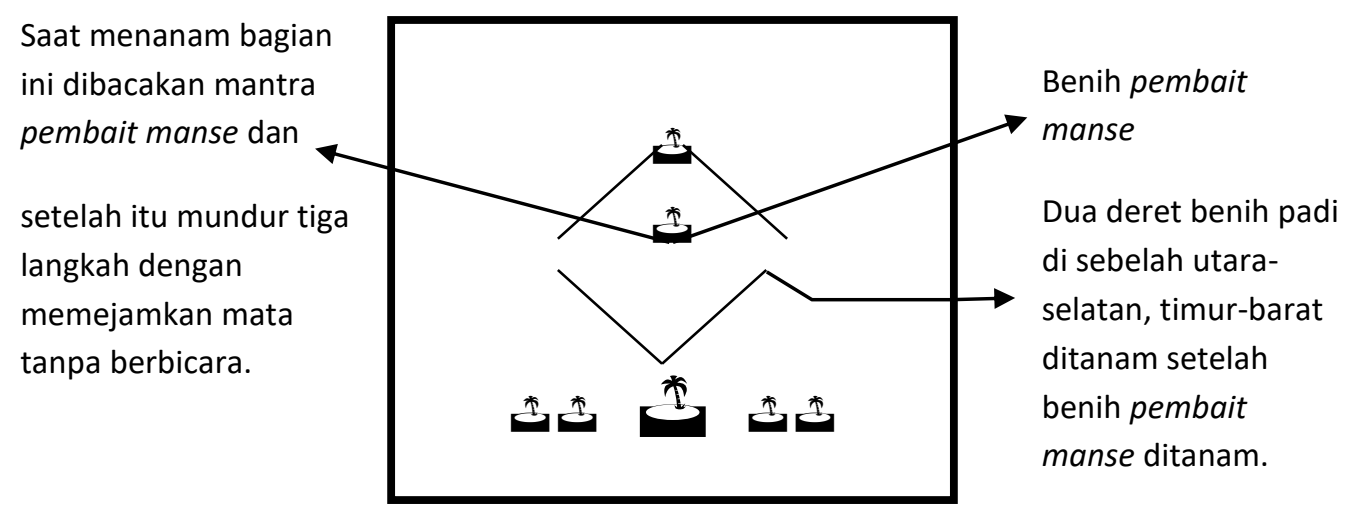

Sumber: Wawancara dengan Bapak Salmun, 6 Oktober 2007 di Jerowaru.

Pelaksanaan bait mansê biasanya dilakukan oleh petani lakilaki. Pada saat prosesi ini berlangsung, si petani membaca mantra pembait mansê berikut. 
(3) Aneh yak kêsodoq êmpat bulan leq bungkak Allah Nabi Adam lemaq aluqm isiq kau birêng mundung bêkupak selakê jiwanggê bêrelong sutêrê bêrate sêlakê.

'Marilah saya titip selama empat bulan di atas "punggung Allah Nabi Adam", nanti saya menjemputmu dengan menggunakan "kerbau hitam mulus", bekupak (kaki bagian paling bawah kerbau) selake jiwangge (nama mata uang dari perak), berekorkan kain sutera, dan berhati selake.'

Selesai pengambilan mansê, para petani akan menunggu untuk menanam bibit padinya selama kurang lebih dua hingga tiga hari. Selanjutnya, ketika menanam padi (lowong) pemilik sawah akan membacakan mantra menanam padi berikut.

(4) Ni Adam yaq sodoq mas tanduran Allah, silaq terimak mas banyu.

'Ini (anak-cucu) Adam akan menitipkan cahaya (nikmat) Allah, terimalah wahai air.'

Perlu diketahui bahwa masyarakat petani Sasak (tradisional) dalam memulai masa tanam padi biasanya akan melihat situasi dan kondisi hari dan bulan untuk mulai menanam. Dalam perhitungan/penanggalan Sasak (tradisional) dikenallah istilah perhitungan dinê dan sasi (hari dan bulan yang baik untuk memulai segala pekerjaan yang baik). Dinê dan sasi yang baik adalah yang tidak memiliki Kalên Bulan dan Kalê Rungkung (wawancara dengan Amaq Salihe, 4 Oktober 2007). ${ }^{2}$

2 Lebih jelas tentang masalah ini bisa diperiksa pada lampiran sistem penanggalan Sasak versi Tikê Limê dan Urigê. 


\subsubsection{Prosesi Pascapenanaman hingga Panen}

Prosesi yang dimaksudkan di sini mulai dari sejak padi sudah mulai berbunga dan keluar bakal buahnya (junjung). Pada saat padi sudah mulai junjung si petani akan sering mengelilingi pematang sawahnya hingga padi tersebut mulai merunduk (ngêrêp) sembari membaca mantra pênamaq sari (pemasuk sari padi). Ada pula yang melakukannya prosesi ini hanya di tempat pengambilan mansê dulu.

(5) Turun buyuq sari emas, sari kuning layar gêntên.

'Turun dan berhimpunlah pada buyuq (padi) ini sari pati emas, sari pati kuning, dengan isi yang berat (barokah).'

Prosesi tentang pemasukan sari ini akan berhenti dilakukan setelah padi mulai menguning. Selama masa tunggu panen, petani Sasak (tradisional) akan sering menyalakan api (berasap) di setiap sudut pematang sawah. Tujuannya adalah untuk mengusir hama penyakit yang hinggap pada padi. Lalu biasanya pada api tersebut akan ditaruhkan garam guna mengusir makhluk halus yang akan mengambil sari padi tersebut.

Ketika musim panen (mataq) tiba, dibuatlah bubur putih dan merah di setiap sudut sawah yang hendak dipanen, yang dibungkus (tétekot) dengan daun pisang. Ini bertujuan untuk mencegah bahaya dari gangguan jin-siluman (makhluk halus). Sesajian ini dibarengi dengan daun sirih, buah pinang, kapur putih, dan rokok, yang berfungsi untuk têmoek-têmariq (menghidangan sesaji) segala jenis makhluk halus yang merusak dan mengganggu hidup manusia. Sesajian yang berupa bubur merah dan putih tersebut dibuatkan pemanggang (ancak-ancak) yang biasanya dari bambu sebagai tempat têtekot yang ditaruh di setiap sudut sawah (Wawancara dengan Bapak Salmun, 6 Oktober 2007). 
Pada saat panen juga, para petani Sasak (tradisional) akan membawa makanan tradisional sasak seperti tikên, sumping, sengkor, topat, dan mpok-pok manisiong. Selain itu juga dibuatkan tontong suit yang dibuat (dimasak) dari beras dan ditaruhi satu butir telur ayam kampung. Penyajian berbagai sesajian tersebut menandakan dimulainya mataq (panen dengan menggunakan rangkêp) sambil membaca mantra:

(6) Aneh nani jaq rateng aluqm isiq kau bireng mundung bekupaq sêlakê jiwanggê bêrelong sutere bêrate sêlakê.

'Sudah saatnya sekarang saya datang menyambutmu dengan "kerbau hitam mulus" bekupak (kaki bagian paling bawah kerbau) selake jiwangge (nama mata uang dari perak), berekorkan kain sutera, dan berhati selake.'

Menurut Bapak Salmun (2007), kegiatan panen dimulai dari tempat dulu dilakukan pengambilan mansê sebesar ukuran gagang sabit (atau sering disebut sênaen basong 'sebesar telapak kaki anjing') dan daun padi tersebut tidak boleh dibuang. Potongan padi dari pembait mansê tadi ditinggalkan di tempat semula (di tengah-tengah sawah) dengan dibuatkan ancak rokoq-lêkês (rokok dan daun sirih yang di dalamnya ada buah pinang, gambir, serta kapur putih yang kemudian digulung), yang ditaruh di dekat potongan padi pembait mansê tadi. Sementara tikên, sumping, dan makanan tradisional lainnya dimakan oleh orang-orang yang ada di sawah atau sekitar sawah tersebut, kemudian bungkusnya dikembalikan lagi pada tempat pengambilan mansê dulu.

Setelah selesai panen satu petak sawah lalu pemilik sawah membawa bagian (tempat pembait mansê) yang ditinggalkan di tengah sawah. Bagian padi yang berasal dari pembait mansê ini kemudian 
dinamakan buyuq. Sesampai di rumah padi-padi tersebut ditungkêp (disusun menyeruapi paramida, tetapi agak bundar). Bagian buyuq tadi ditaruh di bagian tengah tungkêpan padi yang dibuatkan ikên (lapis kepala) sebagai tempat buyuq yang dibuat dari jerami.

Proses selanjutnya adalah penjemuran padi. Pada saat menjemur padi, buyuq ditaruh di tengah-tengah barisan (bantaran) padi. Saat penjemuran padi, buyuq tadi juga dibuatkan ikên yang ditaruh di atas kepala buyuq.

Tahapan berikutnya adalah taliq pare (pengikatan padi). Pada tahap ini, buyuq diikat dengan salah satu dari delapan ikat padi yang lain dengan ukuran ikatan yang besar-besar. Pada saat buyuq dan delapan ikat padi tadi dinaikkan ke alang (lumbung padi) juga dibuatkan dan dibawakan rokoq-lêkês. Buyuq ditaruh di atas kêleong (nyiru). Pada waktu naik tangga membawa buyuq, kaki kanan didahulukan sembari tangga tersebut tepajar (dipesan) dengan membaca bacaan:

(7) Inget tabe-tabe mas anjani aran kamu anjah. Aneh jinsiluman êngkah turut taek leq alang senik, aloh to gumi galuh lain betulung.

'Ingatlah, permisi dan hormat [wahai) mas anjani namamu tangga. Silahkan jin-siluman jangan ikut naik ke atas lumbung ini, silahkan pergi ke bumi luas lainnya [tempatmu] membantu.'

Selesai buyuq tadi ditaruh di dalam lumbung kemudian delapan ikat padi yang menemani buyuq tadi dibawa naik ke atas lumbung dengan menaruhnya di atas nyiru (sebanyak dua ikat) sambil membaca mantra di atas.

Rokoq-lêkês yang dibuatkan untuk buyuq dan delapan ikat padi temannya tadi dibawakan ke atas lumbung sambil membaca mantra di 
atas juga. Adapun tempat ditaruhnya rokoq-lêkês tersebut tepat di atas buyuq tersebut. Empat ikat-empat ikat dari temannya ditaruh di bagian tengah lumbung. Pada setiap sudut dalam lumbung ditaruhkan daun bêrorê. Buyuq tadi ditaruh menghadap Kiblat dengan dibiarkan berdiri sambil dibacakan mantra:

(8) Aneh yaq kesodokm ten adeq ngêrêp têtêp leq dalêm kelambu bayan tilêman padangan santer sari kembang emas pudak karum jayê kêmbang lêngkarang santer sari (3X), aneh adek ngerep tetep dalem kelambu bayan padangan santer sari (3X).

'Mari [saya] akan titipkan dirimu di sini supaya berkumpul menetap di dalam kelambu bayan tilêman padangan santer sari, yang berbunga emas, berbau harum bunga pudak, merekah bak bunga lêngkarang yang penuh dengan sari pati. Ayolah berkumpul menetap dalam lindungan kelambu bayan padangan santer sari.'

\subsubsection{Melacak Pola Pikir dan Kearifan Lokal Masyarakat Sasak}

Setelah mendeskripsikan tentang lika-liku etnobotani masyarakat petani Sasak (tradisional) di atas, banyak hal yang menyita perhatian penulis, terutama terkait dengan data/fakta bahasa di atas yang berupa mantra seputar prosesi penanaman padi hingga panennya, bahkan sampai penempatannya dalam lumbung padi.

Edward Sapir (1884--1939) dan Benjamin Lee Whorf (1897-1941) pernah menyatakan bahwa: “A speaker's perception of the world is organized or constrained by the linguistic categories his or her language offers, that language structure determines thought, how one experiences and hence how one views the world" (Campbell, 2001:99; cf. Crystal, 1992:407; Sampson, 1980:81). 
Berangkat dari pandangan bahwa bahasa membentuk persepsi manusia terhadap realitas dunia luar, dari arah lain, dapat dikatakan bahwa bagaimana penutur bahasa memandang realitas dunia dapat dilihat dari bahasanya. Dengan demikian, penggunaan bahasa tertentu berimplikasi pada bentuk konstruksi realitas dan makna yang dikandungnya. Bahkan, bahasa tidak hanya mampu mencerminkan realitas, tetapi sekaligus dapat menciptakan realitas. Setiap kata, angka, dan simbol lain dalam bahasa yang kita pergunakan -termasuk di dalamnya bahasa mantra- untuk menyampaikan pesan pada orang lain tentulah mengandung makna (cf. Palmer, 1999; Foley, 2001).

Mantra-mantra di atas tentu memiliki makna (signifikansi) karena merupakan suatu simbol atau lambang yang menyimpan nilainilai budaya sehingga dapat digunakan sebagai acuan dalam kehidupan sehari-hari oleh masyarakat pemilik budaya tersebut.

Data bahasa di atas memperlihatkan bahwa mantra merupakan mediator pikiran dan pengontrol sikap/perilaku masyarakat Sasak tani (tradisional) dalam berinteraksi dengan dunia infra-human. Tanah di dalam mantra data (3), misalnya, dimetaforakan dengan istilah bungkak Allah Nabi Adam. Penggunakan istilah tersebut merupakan bentuk penghormatan kepada tanah sebagai asal-muasal penciptaan Nabi Adam (dalam keyakinan agama samawi [Yahudi, Nasrani, dan Islam]), dan merupakan sindiran agar manusia tidak berperilaku rakus terhadap tanah hak orang lain. Hal ini didukung oleh data bahasa Sasak lain, yakni ungkapan bijak yang mengatakan:

Nenggale oleq atas bungkak batur.

[nəygalə ole? atas bUykak batUr]

'Membajak di atas punggung teman' 
Maksud dari ungkapan bijak di atas adalah jangan sampai hak orang lain diserobot atau diambil. Yang berarti, jangan pernah berbahagia di atas penderitaan orang lain.

Potongan-potongan frasa berikut (yang diambil) dari mantramantra di atas menyimpan makna-makna religius-kultural. Perahu bungkêm (2) secara harfiah berarti 'perahu yang tertutup rapat'. Akan tetapi, melihat konteks penggunaannya dalam mantra di atas, maka makna yang paling mendekati adalah 'tanah sawah' itu sendiri yang merupakan ibarat perahu yang tertutup rapat, tidak bocor, sehingga air tidak menyeruak masuk ke dalamnya. Dengan demikian, bahaya tenggelam tidak menimpa perahu. Pemetaforaan sawah dengan perahu bungkêm terungkap lewat adanya kemiripan fungsi dan bentuk. Motivasinya (mungkin) adalah agar benih padi yang sedang direndam itu cepat tumbuh dan siap untuk dibawa berlayar (baca: dibesarkan) ke sawah sebagai perahunya sehingga sampai pada tujuannya, yakni bisa berbuah dan dipanen tepat pada waktunya dengan hasil yang maksimal.

Tanduran Allah (4) berarti 'cahaya Allah', seperti dalam ucapan tanduran gunung yang berarti 'cahaya gunung'. Akan tetapi, dengan memakai analisis paradigmatis ${ }^{3}$ kita bisa memberikan makna yang paling potensial yakni 'rahmat/rizki Allah. Rahmat atau rizki yang diberikan Tuhan kepada makhluk-Nya -dalam pandangan orang Sasak- laksana tanduran atau cahaya. Ia bisa membawa ketenangan dan kebahagiaan ketika disyukuri, tetapi juga menjadi sumber bencana dan kekeruhan hati ketika diingkari. Itulah sebabnya si petani

${ }^{3}$ Analisis paradigmatis adalah analisis yang bertujuan untuk mencari dan memahami sebuah konsep (makna) suatu simbol (kata) dengan cara mengaitkannya dengan konsep-konsep dari simbol-simbol lain yang mendekati dan yang berlawanan. 
menyebut dirinya Adam dalam mantra (4) di atas. Tujuannya ialah supaya ia selalu ingat untuk bersyukur atas nikmat Tuhan yang diberikan kepaadanya, sebagaimana Nabi Adam bersujud kepada Tuhan ketika diperintahkan untuk sujud sebagai bukti dan wujud syukurnya, bukan seperti Iblis yang ingkar terhadap nikmat penciptaannya. Nikmat Tuhan (yang esensial maupun yang wajib) sifatnya hanya sementara, tak ubahnya barang titipan (barang sodoqan) dan cahaya. Bisa terang dan bisa pula redup.

Dari data linguistik nomor (4) di atas, kita juga dapat menangkap pesan nilai kearifan lokal para petani Sasak tradisional yang selalu memperhatikan sistem keyakinan tentang hubungan dengan alam, sehingga dengan halus mereka mengatakan kepada dunia infra-human yang berupa air: "...silaq terimak mas banyu”, yang berarti 'silahkan terima wahai air'.

Sari emas, sari kuning layar gêntên (5). Ungkapan ini merupakan wujud harapan kepada Tuhan agar padi yang sudah mulai berbuah itu benar-benar nantinya menjadi padi yang penuh isi sebagaimana disimbolkan warna emas. Hal itu bertujuan agar warna buah padi itu kuning berisi laksana emas. Sementara frasa sari kuning layar gêntên mengandung makna harapan agar dalam buah padi tersebut tersimpan sari pati makanan yang berkualitas dan barakah, yang nantinya diharapkan bisa menjadi sumber terwujudnya "air suci" asal-muasal kejadian manusia, sehingga menjadi manusia yang berkualitas. Kata gêntên yang secara harfiah berarti 'berat' namun maksudnya adalah nilai barakah pada sari kuning itu.

Adapun maksud dari kau bireng mundung bekupaq sêlakê jiwanggê bêrelong sutere bêrate sêlakê (3 dan 6) adalah kiasan terhadap jenis-jenis sesajian yang dibawa saat prosesi penen padi 
dimulai. Jika pada data nomor (3) ungkapan tersebut diucapkan sebagai janji, maka pada data nomor (6) ungkapan atau mantra tersebut merupakan bentuk pemenuhan (janji).

Istilah Mas Anjani (7) sebagai penyebutan terhadap tangga yang dipakai si pemilik padi yang hendak menaruh padinya ke dalam lumbung tidaklah terlalu mengherankan dalam konteks orang Sasak pedesaan. Kata Anjani memiliki makna kiasan, yakni terkait dengan mitos penghuni dan penguasa tertinggi Gunung Rinjani yang bernama Dewi Anjani, sebagai penguasa (ratu) tertinggi jin-siluman yang ada di bumi Sasak. Hemat penulis, ini semua tidak bisa lepas dari pemahaman nenek-moyang orang Sasak tentang konsep gumi-paer, sebagaimana Gunung Rinjani merupakan konsep pusat kosmos masyarakat Sasak (tradisional) yang ditransformasikan lewat sarana mitologi. Dengan demikian, penyebutan Anjani memiliki motivasi agar segala macam makhluk halus (jin-siluman) tidak berani naik ke atas lumbung untuk mengambil sari pati makanan dalam padi yang telah dihimpun secara simbolik dalam ikatan buyuq dan delapan ikatan pengawalnya.

Mantra nomor (7) di atas tampaknya menyiratkan pesan tentang hubungan mikro kosmos dan makro kosmos. Dalam konteks pemahaman orang Sasak (tradisional), manusia sebagai wujud mikro kosmos menyapa atau berkomunikasi dengan penghuni makro kosmos melalui tiga dimensi alam, yakni alam atas (alam transendental; Tuhan dan para malaikat-Nya), alam tengah/meso (jin), dan alam bawah/infra (bakeq-beraq, beboro, belate, dsb.). Semua dimensi itu sangat berpengaruh dalam ekosistem manusia itu sendiri.

Kelambu bayan tilêman padangan santer sari kembang emas pudak karum jayê kêmbang lêngkarang (8). Fragmen ini memuat 
leksikon bahasa yang sangat estetis. Di samping itu juga, leksikon yang dipakai tergolong sulit untuk dipahami. Kelambu bayan bisa berarti 'tirai yang diruwat dengan sesaji'. Karena kata bayan dalam bahasa Jawa Kuna bisa berarti 'sesaji dan korban'. Mungkin yang dimaksudkan di sini adalah selimutan gaib yang tersimpan dalam ikatan buyuq dan delapan ikat temannya. Tileman berarti 'tempat tidur atau alas tidur' yang diambil dari kata tilam (Jawa Kuna). Padangan 'sinar, cahaya, kejernihan'. Tileman padangan bisa berarti alas tidur atau tempat tidur yang indah dan disinari cahaya, penuh dengan bau harum dan bunga-bungaan (pudak karum jayê kêmbang lêngkarang).

\section{Penutup}

Adanya bentuk-bentuk pemuliaan dan penghormatan pada dunia infra-human melalui penyapaan dengan mantra oleh masyarakat tani Sasak (tradisional) tidak lain hanyalah merupakan bukti tentang adanya hubungan sakral antara manusia dengan alam, dan sekaligus merupakan bentuk penghargaan terhadap sesama makhluk. Misalnya, adanya penyebutan yang bersifat kiasan terhadap air dan tanah tidak semata-mata karena mereka mensakralkan bagian dari dunia infrahuman itu, melainkan sebagai bentuk kesadaran mendasar mereka tentang sebagian asal-muasal penciptaan pertama manusia, tempat kelahiran, sumber-sumber hayati, penopang eksistensi, dan sebagainya dalam mempertahankan ekosistem kehidupan dan penghidupan.

Kita juga dapat mengambil kesimpulan bahwa melalui prosesiprosesi tersebut di atas, masyarakat Sasak tani (tradisional) tidak hanya mengolah alam (baca: bertani) sebagai cara memperoleh materi, tetapi lebih dari itu. Mereka sesungguhnya mengajarkan kita nilai kearifan lokal tentang bagaimana bersahabat dan menjaga harmoni 
dengan alam dan juga membangun nilai kebersamaan dan kerja sama antarsesama makhluk ciptaan Tuhan dengan muatan kepentingan umum.

\section{Daftar Pustaka}

Anwar, Khairul. "Suryasim, Pelestari Urige". Dalam harian Kompas. Rabu, 10 Januari 2007.

Campbell, Lyle. 2001. "The History of Linguistics". Dalam The Handbook of Linguistics. Massachusetts: Blackwell Publishers Inc.

Crystal, David. 1992. The Cambridge Encyclopedia of Language. Cambridge: Cambridge University Press.

Foley, William A. 2001. Anthropological Linguistics: An Introduction. Massachusetts: Blackwell Publisher.

Mahsun. 2005. "Konsep Ruang dalam Bahasa Mbojo dan Kaitannya dengan Cara Pandang Masyarakat Penuturnya." Linguistik Indonesia: Jurnal Ilmiah Mansyarakat Lingistik Indonesia, Tahun ke-23, Nomor 1.

Palmer, Gary B. 1999. Toward a Theory of Cultural Linguistics. Austin: Austin University Press.

Saharudin, 2008. "Sistem Penanggalan Masyarakat Sasak di Lombok NTB" dalam Prosiding Makalah Seminar Nasional Menelusuri Sejarah Penanggalan Nusantara. Yogyakarta: Jurusan Sastra Nusantara Fak. Ilmu Budaya UGM.

Sampson, Geoffrey. 1980. Schools of Linguistics: Competition and Evolution. London: Hutchinson.

Syakur, Ahmad Abd. 2003. "Al-Jamâ'ah Al-Islâmiyyah Wetu Telu Bi Jazîrati Lombok.” Millah: Jurnal Studi Agama, Vol. III, No. 1. Yogyakarta: Magister Studi Islam Universitas Islam Indonesia. 
